Article

\title{
Lignin Hydrolysis and Phosphorylation Mechanism during Phosphoric Acid-Acetone Pretreatment: A DFT Study
}

\author{
Wu Qin *, Lingnan Wu, Zongming Zheng *, Changqing Dong and Yongping Yang \\ National Engineering Laboratory for Biomass Power Generation Equipment, School of Renewable \\ Energy Engineering, North China Electric Power University, Beijing 102206, China \\ * Authors to whom correspondence should be addressed; E-Mails: qinwugx@126.com (W.Q.); \\ zmzheng@vip.126.com (Z.Z.); Tel.: +86-10-6177-2457 (W.Q.); Fax: +86-10-6177-2031 (W.Q.).
}

External Editor: Derek J. McPhee

Received: 11 October 2014; in revised form: 7 December 2014 / Accepted: 8 December 2014 / Published: 18 December 2014

\begin{abstract}
The study focused on the structural sensitivity of lignin during the phosphoric acid-acetone pretreatment process and the resulting hydrolysis and phosphorylation reaction mechanisms using density functional theory calculations. The chemical stabilities of the seven most common linkages ( $\beta-O-4, \beta-\beta, 4-O-5, \beta-1,5-5, \alpha-O-4$, and $\beta-5)$ of lignin in $\mathrm{H}_{3} \mathrm{PO}_{4}, \mathrm{CH}_{3} \mathrm{COCH}_{3}$, and $\mathrm{H}_{2} \mathrm{O}$ solutions were detected, which shows that $\alpha-O-4$ linkage and $\beta-O-4$ linkage tend to break during the phosphoric acid-acetone pretreatment process. Then $\alpha-O-4$ phosphorylation and $\beta-O-4$ phosphorylation follow a two-step reaction mechanism in the acid treatment step, respectively. However, since phosphorylation of $\alpha-O-4$ is more energetically accessible than phosphorylation of $\beta-O-4$ in phosphoric acid, the phosphorylation of $\alpha-O-4$ could be controllably realized under certain operational conditions, which could tune the electron and hole transfer on the right side of $\beta-O-4$ in the $\mathrm{H}_{2} \mathrm{PO}_{4}{ }^{-}$functionalized lignin. The results provide a fundamental understanding for process-controlled modification of lignin and the potential novel applications in lignin-based imprinted polymers, sensors, and molecular devices.
\end{abstract}

Keywords: lignin; lignocellulose; biomass; pretreatment; DFT 


\section{Introduction}

Lignin is a complex polymer of aromatic alcohols mostly derived from wood [1,2] and accounting for $15 \%-20 \%$ of lignocelluloses [3]. Lignin plays important roles in resistance to pests and diseases, and nutrient transport with sunlight and frost stress responses [4]. The advantages of using organosolv lignin in the production of phenolic resins include a reduction in the consumption of formaldehyde and enhancement of the resulting resins' wear behavior [5]. Lignin derivatives have been used to produce epoxy resins, polyurethane and isocyanurate resins [6]. Lignin can be blended with natural polymers (e.g., starch), acts as an antioxidant or flame-retardant agent, and absorbs UV radiation [4]. The incorporation of epoxy-modified lignosulfonate into a polypropylene/polyethylene compatibilizing agent produced a polymer with good thermal, physico-mechanical, and surface properties [7]. Lignin could be used as a binder in mortar and construction systems and for metal sequestration in solutions. The sulfur-free lignin isolated from pulping has been tested as a mortar additive [8]. It was found to be comparable in performance to commercially available lignins, such as Organocell, Alcell, and Curan100. The industrial lignins obtained from different sources exhibit high antioxidant capacity over a range of concentrations, suggesting the potential use of lignins in cosmetic and topical medical formulations [9]. The PLA/APP/PER composite containing lignin shows lower limiting oxygen index values, but it is still commercially acceptable. The UL-94 ratings are superior to that containing pentaerythritol [10]. For these important applications of lignin, research turns to how obtain lignin from biomass.

Recently, the phosphoric acid-acetone pretreatment process represents one of the most efficient methods to separate lignin and cellulose from lignocellulose, where bonds between lignin and cellulose break and cellulose dissolves into $\mathrm{H}_{3} \mathrm{PO}_{4}$, then the dissolved cellulose sediments in acetone while the lignin dissolves in the acetone [11-14]. Figure 1 shows the principle of the phosphoric acid-acetone pretreatment process.

Figure 1. The phosphoric acid-acetone pretreatment process.

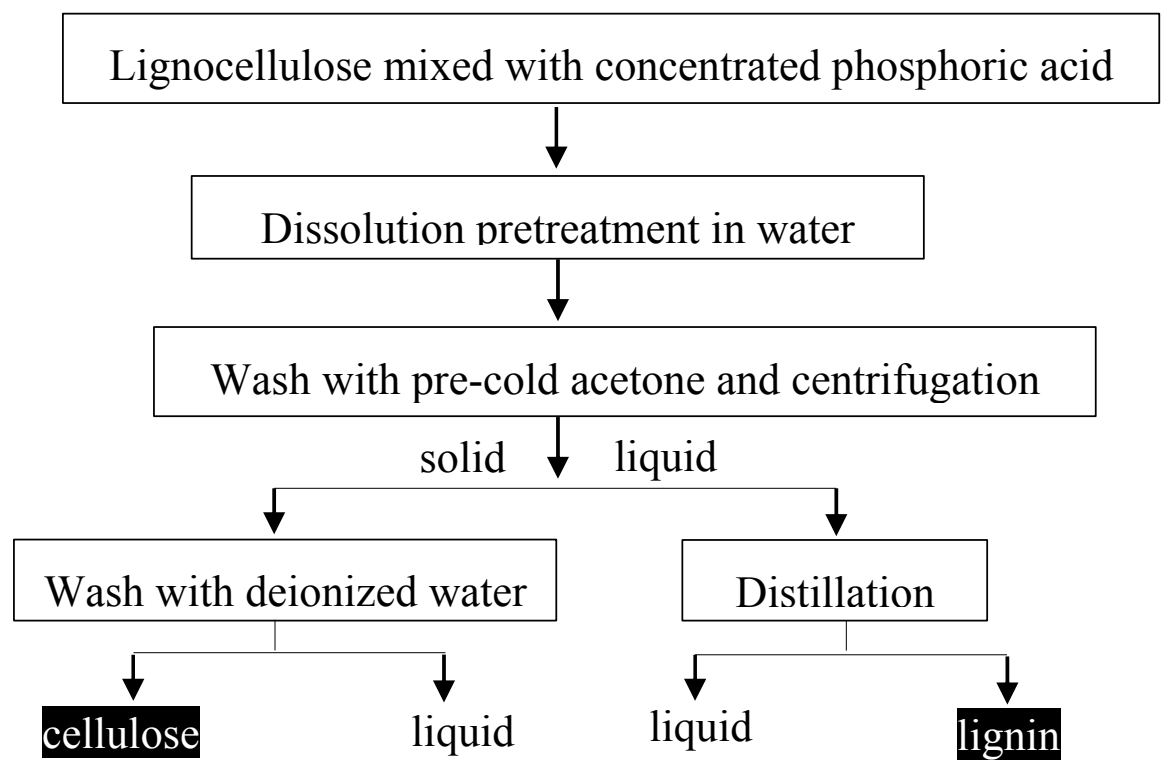

In these processes, $\mathrm{H}_{3} \mathrm{PO}_{4}$ is a weak triprotic acid, non-toxic and inexpensive compared with other mineral acids. Cellulose can be dissolved in phosphoric acid more simply, faster and at lower 
temperatures. The hydrogen ions from $\mathrm{H}_{3} \mathrm{PO}_{4}$ could be easily diffused into cellulose [15]. Two phenomena occur after dissolution: the first one is that an esterification reaction that happens between the hydroxyl groups of cellulose and $\mathrm{H}_{3} \mathrm{PO}_{4}$ to form cellulose phosphate, and a competition of hydrogen-bond formation among the remaining hydroxyl groups on cellulose chains, a hydrogen ion and a water molecule; the second case is that the pretreated cellulose changes into amorphous cellulose after phosphoric acid pretreatment [11]. The amorphous regions bundle with the remaining crystalline structure of cellulose, resulting in the uneven and rough molecular surface. Moreover, the pretreated cellulose reaches its adsorption equilibrium in a relatively shorter time, suggesting that $\mathrm{H}_{3} \mathrm{PO}_{4}$ pretreatment can accelerate the enzyme adsorption rate and enhance the subsequent hydrolysis process. However, limited attention has been played to the behavior of lignin in the phosphoric acid-acetone pretreatment process. The detailed interaction between lignin and solution, the related reaction mechanism and the resulting modified properties of the lignin remain unknown.

To address these fundamental questions, we used models for the seven most common linkages in lignin (accounting for approximately 87\% of linkages in softwood lignin [16]) to detect the chemical stability of these seven linkages to reveal in details the sensitivity of lignin, the hydrolysis and phosphorylation occurring to the vulnerable linkages, and the process-tuned properties of the modified lignin.

\section{Results and Discussion}

\subsection{Decomposition of Lignin in Various Solutions}

Models of the model lignin with the most common linkages $(\beta-O-4, \alpha-O-4,5-5, \beta-1, \beta-5, \beta-\beta$, and 4-O-5) were built in reference to the work of Beste [17]. Figure 2 shows the stable configuration of the model lignin and the calculated potential energy profiles for the decomposition of the seven linkages in $\mathrm{H}_{2} \mathrm{O}, \mathrm{CH}_{3} \mathrm{COCH}_{3}$, and $\mathrm{H}_{3} \mathrm{PO}_{4}$ solutions. The reactions start from the optimized geometries of $\beta-O-4$, $\alpha-O-4,5-5, \beta-1, \beta-5, \beta-\beta$, and $4-O-5$ in these different solutions, respectively. The energy barrier $\left(E_{\mathrm{a}}\right)$ for $\beta$-O-4 decomposition in $\mathrm{H}_{2} \mathrm{O}, \mathrm{CH}_{3} \mathrm{COCH}_{3}$, and $\mathrm{H}_{3} \mathrm{PO}_{4}$ solutions is $55.2 \mathrm{kcal} / \mathrm{mol}, 60.4 \mathrm{kcal} / \mathrm{mol}$, and $55.5 \mathrm{kcal} / \mathrm{mol}$, respectively, while the reaction energy $\left(E_{\mathrm{r}}\right)$ is $54.1 \mathrm{kcal} / \mathrm{mol}, 53.544 \mathrm{kcal} / \mathrm{mol}$, and $55.2 \mathrm{kcal} / \mathrm{mol}$. $E_{\mathrm{a}}$ and $E_{\mathrm{r}}$ for $\alpha-O-4$ decomposition in $\mathrm{H}_{2} \mathrm{O}, \mathrm{CH}_{3} \mathrm{COCH}_{3}$, and $\mathrm{H}_{3} \mathrm{PO}_{4}$ solutions is $42.8 \mathrm{kcal} / \mathrm{mol}$ and $12.2 \mathrm{kcal} / \mathrm{mol}, 53.2 \mathrm{kcal} / \mathrm{mol}$ and $42.5 \mathrm{kcal} / \mathrm{mol}, 44.1 \mathrm{kcal} / \mathrm{mol}$ and $19.8 \mathrm{kcal} / \mathrm{mol}$, respectively. $E_{\mathrm{a}}$ and $E_{\mathrm{r}}$ for 5-5 decomposition in $\mathrm{H}_{2} \mathrm{O}, \mathrm{CH}_{3} \mathrm{COCH}_{3}$, and $\mathrm{H}_{3} \mathrm{PO}_{4}$ solutions is $138.6 \mathrm{kcal} / \mathrm{mol}$ and $131.9 \mathrm{kcal} / \mathrm{mol}, 140.1 \mathrm{kcal} / \mathrm{mol}$ and $139.2 \mathrm{kcal} / \mathrm{mol}, 138.3 \mathrm{kcal} / \mathrm{mol}$ and $138.0 \mathrm{kcal} / \mathrm{mol}$, respectively. $E_{\text {a }}$ and $E_{\mathrm{r}}$ for $\beta-1$ decomposition in $\mathrm{H}_{2} \mathrm{O}, \mathrm{CH}_{3} \mathrm{COCH}_{3}$, and $\mathrm{H}_{3} \mathrm{PO}_{4}$ solutions is $133.0 \mathrm{kcal} / \mathrm{mol}$ and $132.4 \mathrm{kcal} / \mathrm{mol}, 133.1 \mathrm{kcal} / \mathrm{mol}$ and $132.2 \mathrm{kcal} / \mathrm{mol}, 130.7 \mathrm{kcal} / \mathrm{mol}$ and $129.6 \mathrm{kcal} / \mathrm{mol}$, respectively. $E_{\mathrm{a}}$ and $E_{\mathrm{r}}$ for $\beta-5$ decomposition in $\mathrm{H}_{2} \mathrm{O}, \mathrm{CH}_{3} \mathrm{COCH}_{3}$, and $\mathrm{H}_{3} \mathrm{PO}_{4}$ solutions is $100.3 \mathrm{kcal} / \mathrm{mol}$ and $97.5 \mathrm{kcal} / \mathrm{mol}, 97.4 \mathrm{kcal} / \mathrm{mol}$ and $93.3 \mathrm{kcal} / \mathrm{mol}, 95.8 \mathrm{kcal} / \mathrm{mol}$ and $92.2 \mathrm{kcal} / \mathrm{mol}$, respectively. $E_{\text {a }}$ and $E_{\mathrm{r}}$ for $\beta-\beta$ decomposition in $\mathrm{H}_{2} \mathrm{O}, \mathrm{CH}_{3} \mathrm{COCH}_{3}$, and $\mathrm{H}_{3} \mathrm{PO}_{4}$ solutions is $134.1 \mathrm{kcal} / \mathrm{mol}$ and $116.1 \mathrm{kcal} / \mathrm{mol}$, $95.6 \mathrm{kcal} / \mathrm{mol}$ and $85.6 \mathrm{kcal} / \mathrm{mol}, 103.2 \mathrm{kcal} / \mathrm{mol}$ and $96.4 \mathrm{kcal} / \mathrm{mol}$, respectively. $E_{\mathrm{a}}$ and $E_{\mathrm{r}}$ for $4-O-5$ decomposition in $\mathrm{H}_{2} \mathrm{O}, \mathrm{CH}_{3} \mathrm{COCH}_{3}$, and $\mathrm{H}_{3} \mathrm{PO}_{4}$ solutions is $88.2 \mathrm{kcal} / \mathrm{mol}$ and $84.9 \mathrm{kcal} / \mathrm{mol}, 82.2 \mathrm{kcal} / \mathrm{mol}$ and $82.0 \mathrm{kcal} / \mathrm{mol}, 85.4 \mathrm{kcal} / \mathrm{mol}$ and $82.4 \mathrm{kcal} / \mathrm{mol}$, respectively. The results imply that energetically $5-5, \beta-1, \beta-5, \beta-\beta$, and $4-O-5$ are rather chemically stable during the phosphoric acid-acetone pretreatment 
process, which can maintain the structural integrity and the yield of lignin during the pretreatment process [18]. However, partial structural damage happens to lignin due to the relative vulnerability of $\beta-O-4$ and $\alpha-O-4$, and as mentioned before that $\beta-O-4$ is one of the main cleavage modes [19] and the dissociation enthalpy of $\alpha-O-4$ is small (40-44 kcal/mol in gas phase) [20]. Interestingly, the breakage of $\alpha-O-4$ linkages resulted in relatively permanent damage to lignin, since it is relatively difficult for the reverse process of the decomposition to happen due to the higher activation energy $\left(\overleftarrow{E_{a}}\right)$ for the reverse reaction in $\mathrm{H}_{2} \mathrm{O}$ and $\mathrm{H}_{3} \mathrm{PO}_{4}$ solutions, compared to the decomposition process of $\beta-O-4$ linkage. These results are similar to the work reported by Kim et al. [21].

Figure 2. (a) Stable lignin fragment highlighting the linkages studied in this work: (A) $\beta-O-4$; (B) $\beta-\beta$; (C) $4-O-5$; (D) $\beta-1$; (E) $5-5$; (F) $\alpha-O-4$; and (G) $\beta-5$; (b) Potential energy profiles for the decomposition reaction of different linkages in $\mathrm{H}_{3} \mathrm{PO}_{4}, \mathrm{CH}_{3} \mathrm{COCH}_{3}$, and $\mathrm{H}_{2} \mathrm{O}$ solutions.

(a) A)
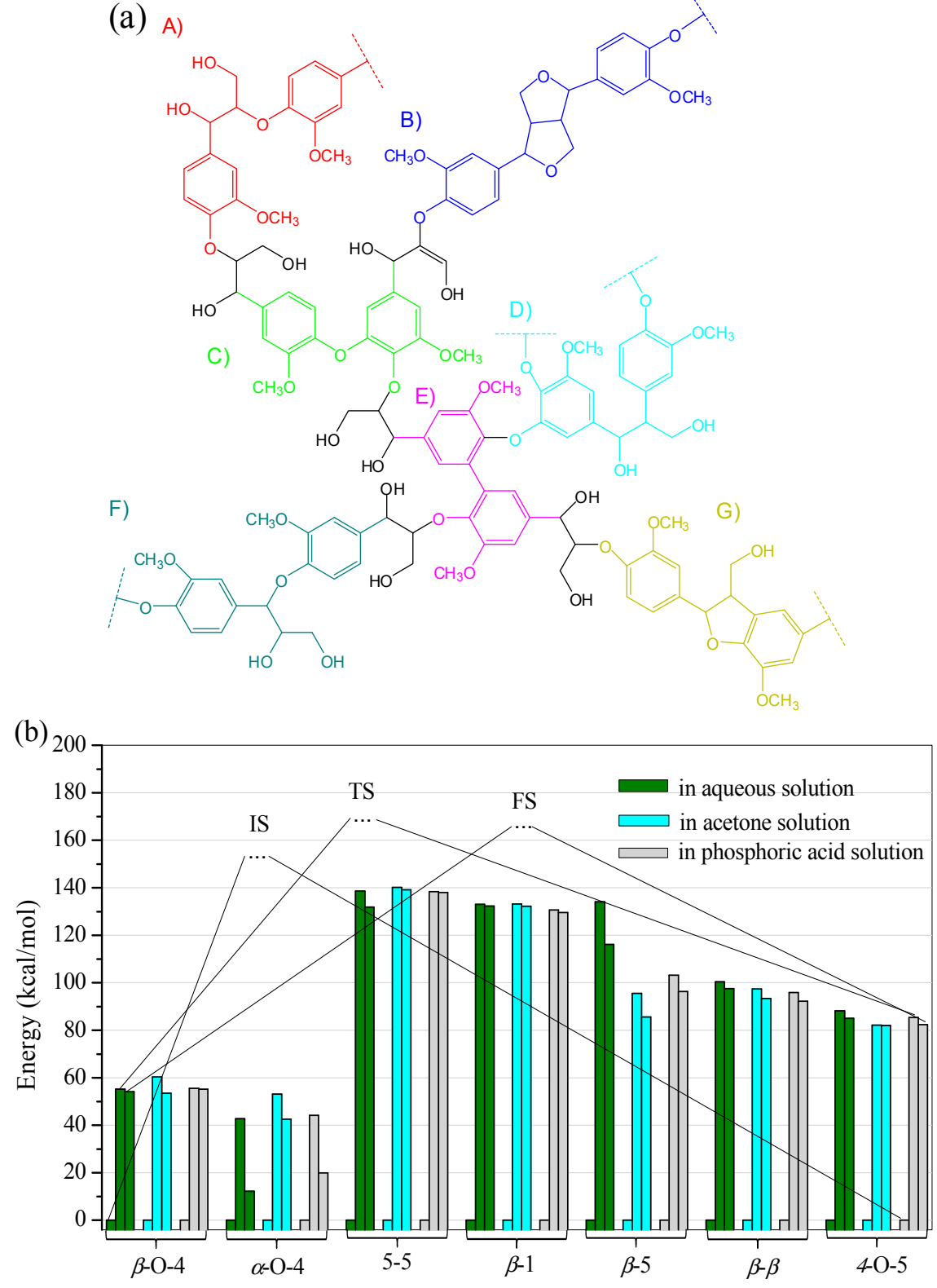
The charge density difference of the system at the critical points, i.e., initial state (IS), transition state (TS), and final state (TS) of the decomposition reaction of $\beta-O-4, \alpha-O-4,5-5, \beta-1, \beta-5, \beta-\beta$, and $4-O-5$, respectively, is further discussed. The different density isosurfaces for the $\beta-O-4, \alpha-O-4,5-5, \beta-1, \beta-5$, $\beta-\beta$ and 4-O-5 linkage are symmetric at IS. However, at TS and FS, the electron density is enriched at the $\mathrm{O}$ atom of the $\beta-O-4, \alpha-O-4$ and $4-O-5$ linkage, respectively, while the electron density is depleted at the corresponding $\mathrm{C}_{\beta}, \mathrm{C}_{\alpha}$, and $\mathrm{C}_{4}$ atom; for the $\beta-1$ and $\beta-5$ linkages, the electron density is enriched at one $\mathrm{C}_{\beta}$ atom and depleted at the $\mathrm{C}_{1}$ atom and $\mathrm{C}_{5}$ atom, respectively; also for the 5-5 and $\beta$ - $\beta$ linkages, the electron density is enriched at one $\mathrm{C}$ atom and depleted at the other $\mathrm{C}$ atom, respectively. The partial electron transfer through the reaction resulted in an unsymmetrical electron density population, which implies that the decomposition of $\beta-O-4, \alpha-O-4,5-5, \beta-1, \beta-5, \beta-\beta$, and $4-O-5$ in these solutions will proceed via a heterolytic, unzipping mechanism, as described in the work of Sturgeon et al. [22].

\subsection{Phosphorylation of Lignin}

Further, we focused on the phosphorylation mechanism of lignin. Figure 3 compares the calculated potential energy profiles for the direct one-step phosphorylation and two-step phosphorylation of $\beta-O-4$ and $\alpha-O-4$. The one-step reaction channel starts from the optimized adsorption geometries of $\mathrm{H}_{3} \mathrm{PO}_{4}$ on $\beta-O-4$ and $\alpha-O-4$, respectively.

Figure 3. The calculated potential energy profiles for the direct one-step phosphorylation of lignin at (a) $\alpha-O-4$ linkage and at (b) $\beta-O-4$ linkage, and the referenced two-step phosphorylation of the decomposed lignin.

(a)

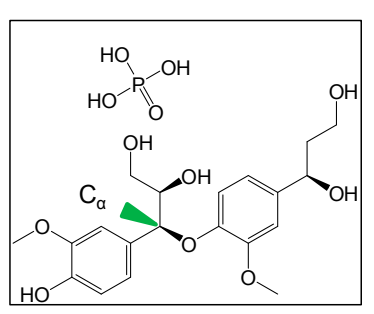

$\mathrm{IS}=0.0 \mathrm{kcal} / \mathrm{mol}$

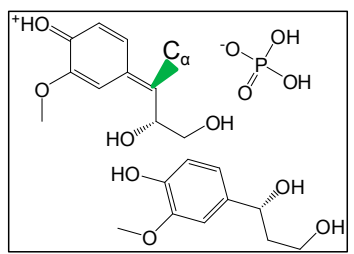

$\mathrm{TS}=49.7 \mathrm{kcal} / \mathrm{mol}$

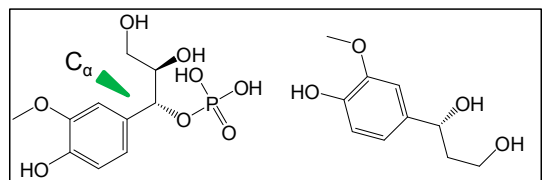

$\mathrm{FS}=-0.5 \mathrm{kcal} / \mathrm{mol}$

Path-1

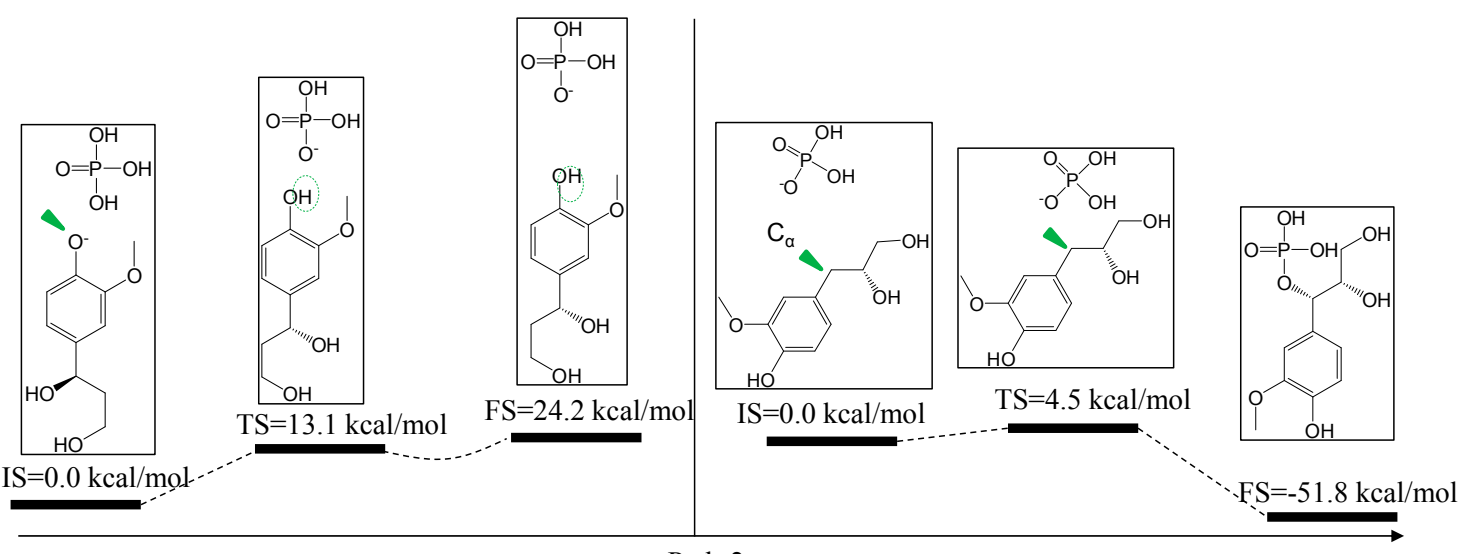

Path-2 
Figure 3. Cont.

(b)
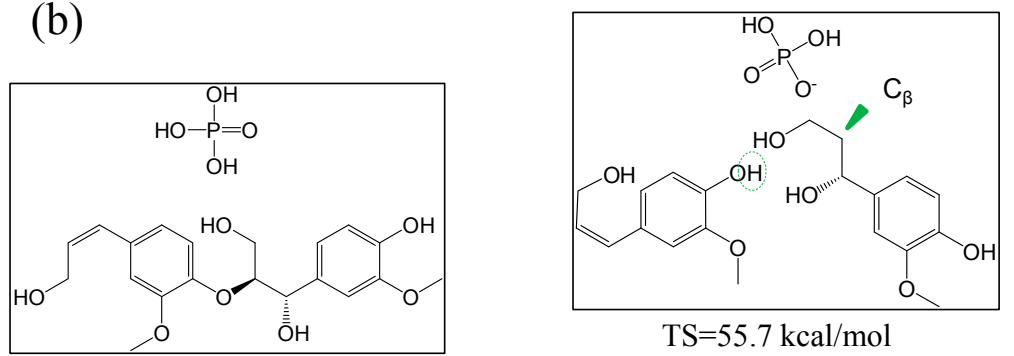

$\mathrm{TS}=55.7 \mathrm{kcal} / \mathrm{mol}$

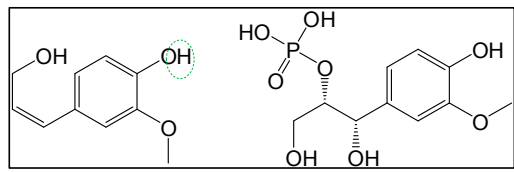

IS $=0.0 \mathrm{kcal} / \mathrm{mol}$
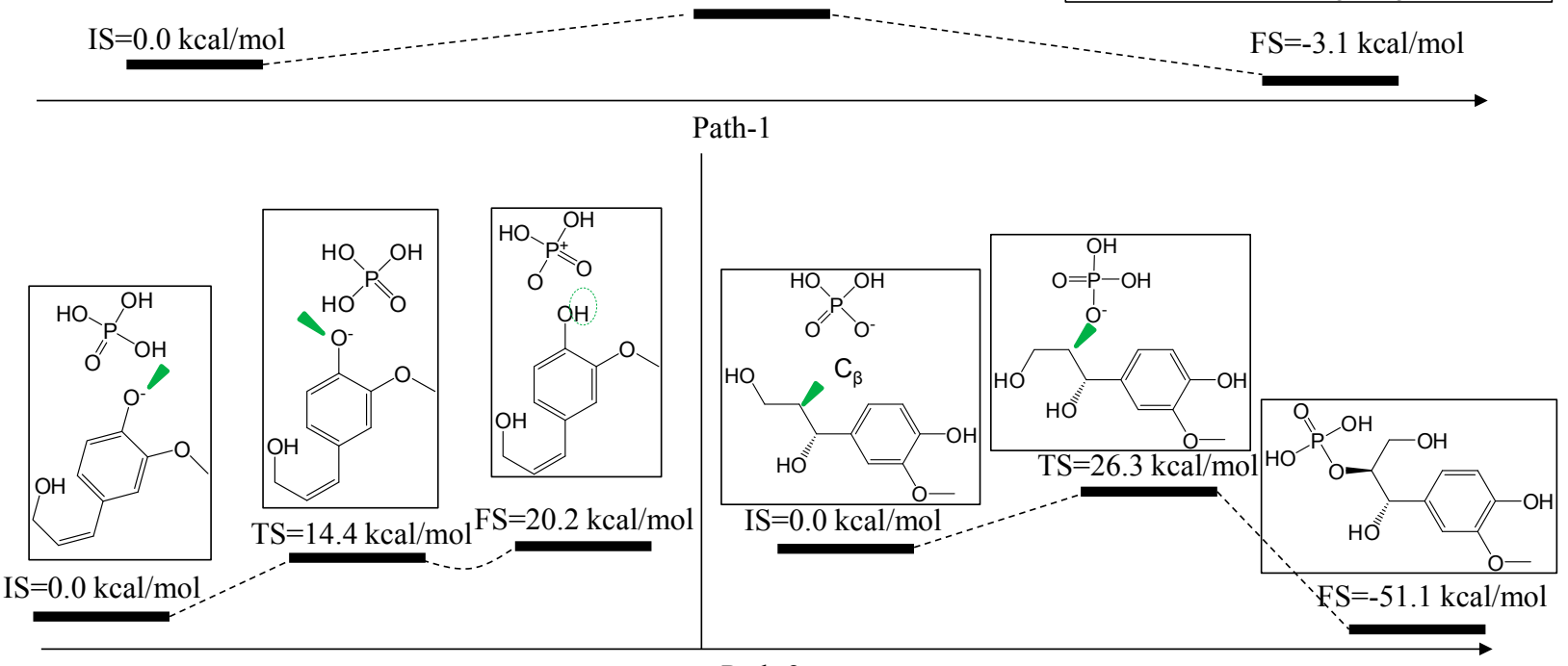

Path-2

The two-step reaction channel starts from the stable adsorption of $\mathrm{H}_{3} \mathrm{PO}_{4}$ to the $\mathrm{O}$ site (shown with the green arrow in the lower part of Figures 3 and 4 ) of the decomposed $\beta-O-4$ and $\alpha-O-4$; then $\mathrm{H}^{+}$from $\mathrm{H}_{3} \mathrm{PO}_{4}$ bonded to the $\mathrm{O}$ site of part of the decomposed $\beta-O-4$ and $\alpha-O-4$ and $\mathrm{H}_{2} \mathrm{PO}_{4}{ }^{-}$bonded to $\mathrm{C}_{\beta}$ and $\mathrm{C}_{\alpha}$ of the other part of the decomposed $\beta-O-4$ and $\alpha-O-4$ at the final state, respectively.

$E_{\mathrm{a}}$ for the direct one-step phosphorylation of $\alpha-O-4$ is $49.8 \mathrm{kcal} / \mathrm{mol}$, which is higher than that of the decomposition of $\alpha-O-4(44.1 \mathrm{kcal} / \mathrm{mol}$ shown in Figure 2$)$ in phosphoric acid. Also, the $E_{\mathrm{a}}$ for the two step mechanism of phosphorylation of $\alpha-O-4$ is far lower than $49.7 \mathrm{kcal} / \mathrm{mol}$, therefore, $\alpha-O-4$ prefers to follow the two-step phosphorylation mechanism based on the decomposition of $\alpha-O-4$ with the relatively lower $E_{\mathrm{a}}$ of $44.1 \mathrm{kcal} / \mathrm{mol}$.

$E_{\text {a }}$ for the direct one-step phosphorylation of $\beta-O-4$ is $55.7 \mathrm{kcal} / \mathrm{mol}$, which is a bit higher than that of the decomposition of $\beta-O-4$ (55.5 kcal/mol shown in Figure 2). $E_{\text {a }}$ for the two step mechanism of phosphorylation of $\beta-O-4$ is far lower than $55.5 \mathrm{kcal} / \mathrm{mol}$. Therefore, $\beta-O-4$ prefers to follow a two-step phosphorylation mechanism.

According to the calculated $E_{\mathrm{a}}$, phosphorylation of $\alpha-O-4$ is more energetically accessible than phosphorylation of $\beta-O-4$ during the treatment of lignin in phosphoric acid. After phosphorylation, $\mathrm{H}_{2} \mathrm{PO}_{4}^{-}$bound to $\mathrm{C}_{\beta}$ and $\mathrm{C}_{\alpha}$, respectively, while $\mathrm{H}^{+}$bound the corresponding $\mathrm{O}$ atom binding to the aromatic ring of the decomposed $\alpha-O-4$ and $\beta-O-4$. The stable configuration of $\mathrm{H}_{2} \mathrm{PO}_{3}$-lignin species was obtained after lignin phosphorylation in $\mathrm{H}_{2} \mathrm{PO}_{3}$ solution, which corresponds to the product of the reaction between lignin and phosphorous oxychloride in the presence of pyridine [23]. 


\subsection{Hydrolysis of Lignin}

In reference to the theoretical study on acid-catalyzed hydrolysis of lignin $\beta-O-4$ linkages in ionic liquid solvents [24], we focused on the hydrolysis mechanism of lignin. Figure 4 shows the same energy profiles as Figure 3, but for the hydrolysis of lignin. $E_{\text {a }}$ for the direct one-step hydrolysis of $\alpha-O-4$ is $56.8 \mathrm{kcal} / \mathrm{mol}$, which is higher than that of the decomposition of $\alpha-O-4(42.6 \mathrm{kcal} / \mathrm{mol}$ shown in Figure 2) in aqueous solution. $E_{\text {a }}$ for the two-step mechanism of hydrolysis of $\alpha-O-4$ is lower than $56.8 \mathrm{kcal} / \mathrm{mol}$, therefore, $\alpha-O-4$ prefers to follow the two-step hydrolysis mechanism based on the decomposition of $\alpha-O-4$ in aqueous solution.

$E_{\text {a }}$ for the direct one-step hydrolysis of $\beta-O-4$ is $52.3 \mathrm{kcal} / \mathrm{mol}$, which is a bit lower than that of the decomposition of $\beta-O-4$ (55.2 kcal/mol shown in Figure 2). However, though the $E_{\text {a }}$ for the two-step mechanism of hydrolysis of $\beta-O-4$ is far lower than $52.3 \mathrm{kcal} / \mathrm{mol}$, the premise is that the two step reactions are based on the decomposition of $\beta-O-4$ with the $E_{\text {a }}$ of $55.2 \mathrm{kcal} / \mathrm{mol}$ in aqueous solution.

Figure 4. The calculated potential energy profiles for the direct one-step hydrolysis of lignin (a) $\alpha-O-4$ linkage and at (b) $\beta-O-4$ linkage, and the referenced two-step hydrolysis of the decomposed lignin.

(a)
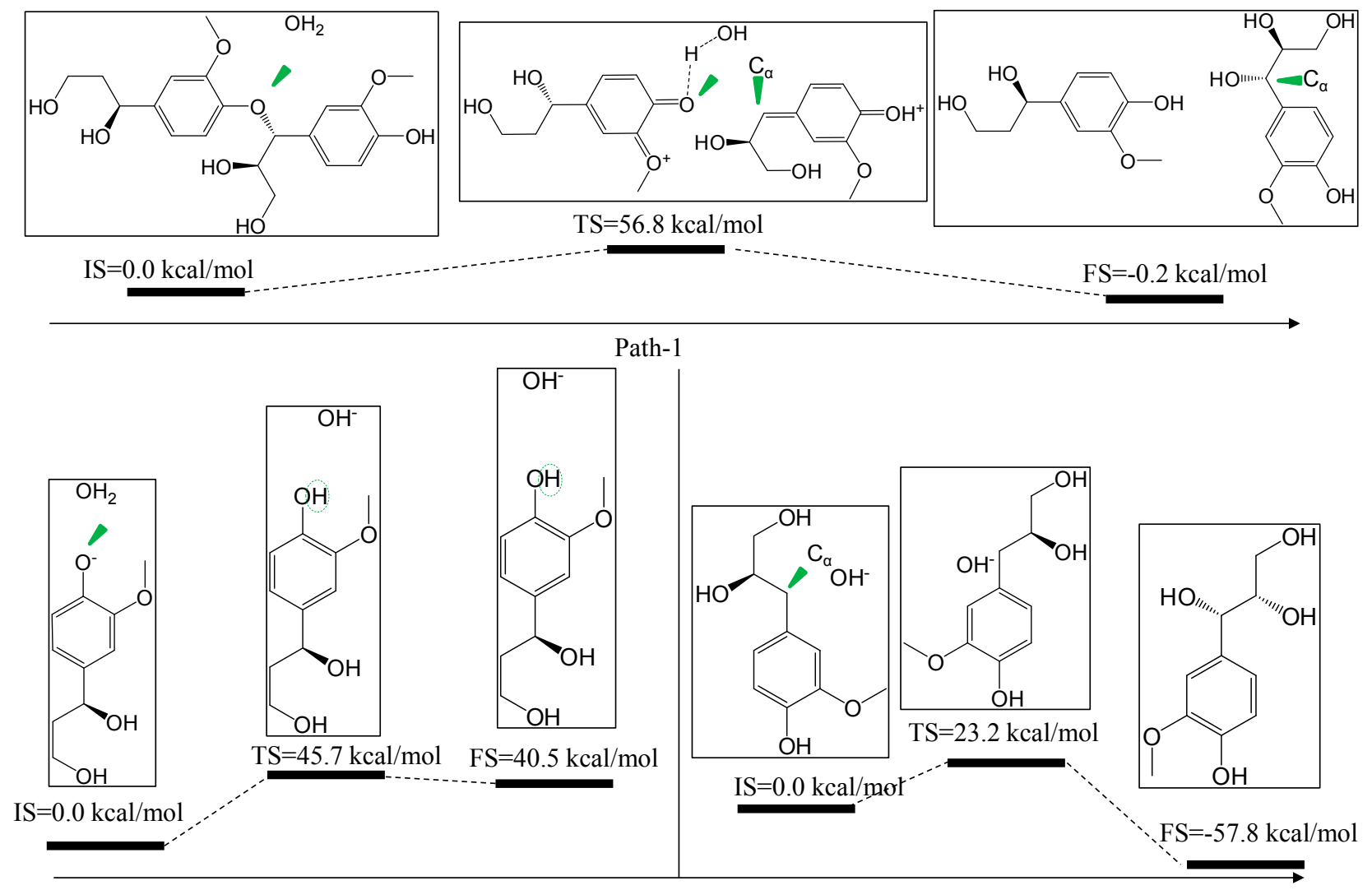

Path-2 
Figure 4. Cont.

(b)

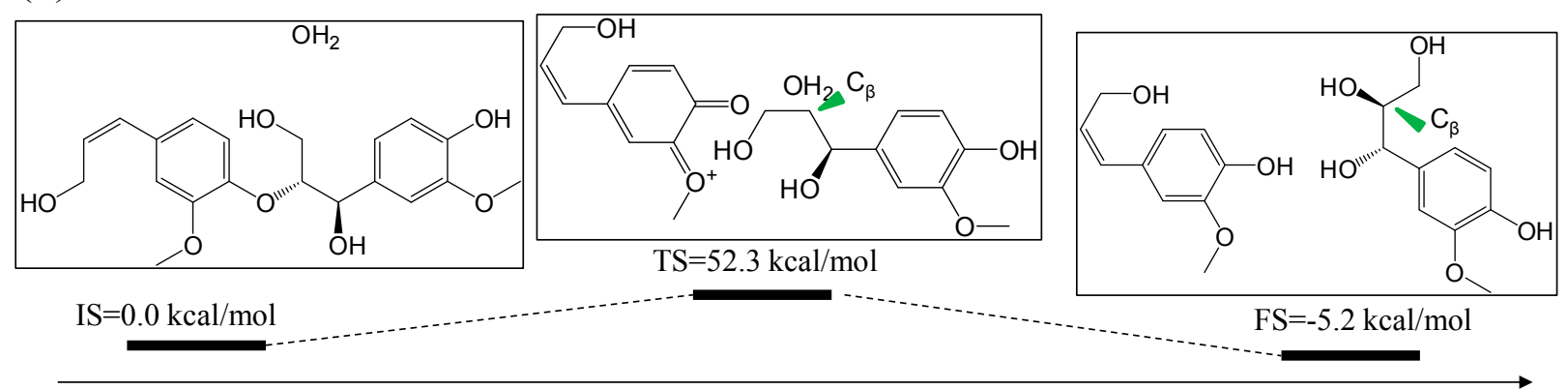

Path-1

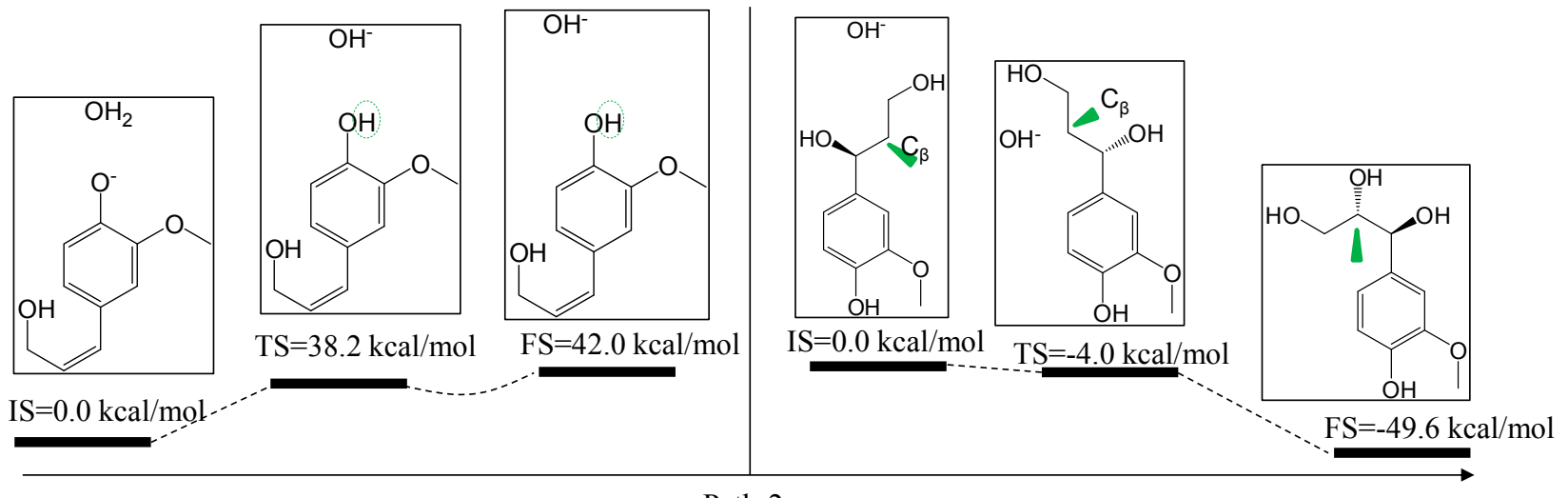

Path-2

Therefore, $\beta-O-4$ prefers to follow a one-step hydrolysis mechanism in aqueous solution. After hydrolysis of the $\alpha-O-4$ and $\beta-O-4, \mathrm{HO}^{-}$bonds to $\mathrm{C}_{\beta}$ and $\mathrm{C}_{\alpha}$, respectively, while $\mathrm{H}^{+}$bonds to the corresponding $\mathrm{O}$ atom linking to the aromatic ring of lignin.

Comparing Figures 3 and 4, we observed that phosphorylation and hydrolysis of $\alpha-O-4$ follow a two-step reaction mechanism, while phosphorylation and hydrolysis of $\beta-O-4$ follow a one-step reaction mechanism. Due to the relatively small $E_{\mathrm{a}}, \alpha-O-4$ and $\beta-O-4$ could phosphorylate and hydrolyze in phosphoric acid and aqueous solution, respectively. However, phosphoric acid treatment is the first step of the phosphoric acid-acetone pretreatment process, hence the two-step phosphorylation reaction of $\alpha-O-4$ and the one-step phosphorylation reaction of $\beta-O-4$ would occur at this acid treatment step. Further, since phosphorylation of $\alpha-O-4$ is more energetically accessible than phosphorylation of $\beta-O-4$ in phosphoric acid, the phosphorylation of $\alpha-O-4$ could be controllably realized under certain operational condition.

\subsection{Properties of the Obtained Lignin}

Hydrolysis and phosphorylation of lignin occur during the phosphoric acid-acetone pretreatment process, which can modify the properties of lignin. For example, - $\mathrm{OH}$ groups provide an opportunity to create hydrogen bonds between copolymer and lignin [25]; incorporation of $\mathrm{H}_{2} \mathrm{PO}_{4}{ }^{-}$group into lignin enhances the adsorption ability of lignin to metal ions [26]. Herein, we revealed how the -OH group and $\mathrm{H}_{2} \mathrm{PO}_{4}{ }^{-}$group modify the electronic properties of lignin at an atomic level. Figure 5 compares the density of state (DOS) for the pure model lignin containing the most common linkages (shown in Figure 2), the $\mathrm{HO}$-functionalized lignin, and the $\mathrm{H}_{2} \mathrm{PO}_{4}$-functionalized lignin. In comparison with the DOS for the pure 
lignin and the $\mathrm{HO}$-functionalized lignin, $\mathrm{H}_{2} \mathrm{PO}_{4}-\mathrm{C}_{\beta}$ and $\mathrm{H}_{2} \mathrm{PO}_{4}-\mathrm{C}_{\alpha}$ change the DOS obviously. Electrons of $\mathrm{H}_{2} \mathrm{PO}_{4}-\mathrm{C}_{\beta}$ lignin and $\mathrm{H}_{2} \mathrm{PO}_{4}-\mathrm{C}_{\alpha}$ lignin are highly delocalized near and below the Fermi level. Both hydrolysis and phosphorylation to $\alpha-O-4$ linkage decrease the energy gap between the highest occupied molecular orbit (HOMO) and the lowest unoccupied molecular orbit (LUMO) of lignin.

Figure 5. DOS for the pure lignin, $\mathrm{HO}$-functionalized lignin, and the $\mathrm{H}_{2} \mathrm{PO}_{4}$-functionalized lignin.

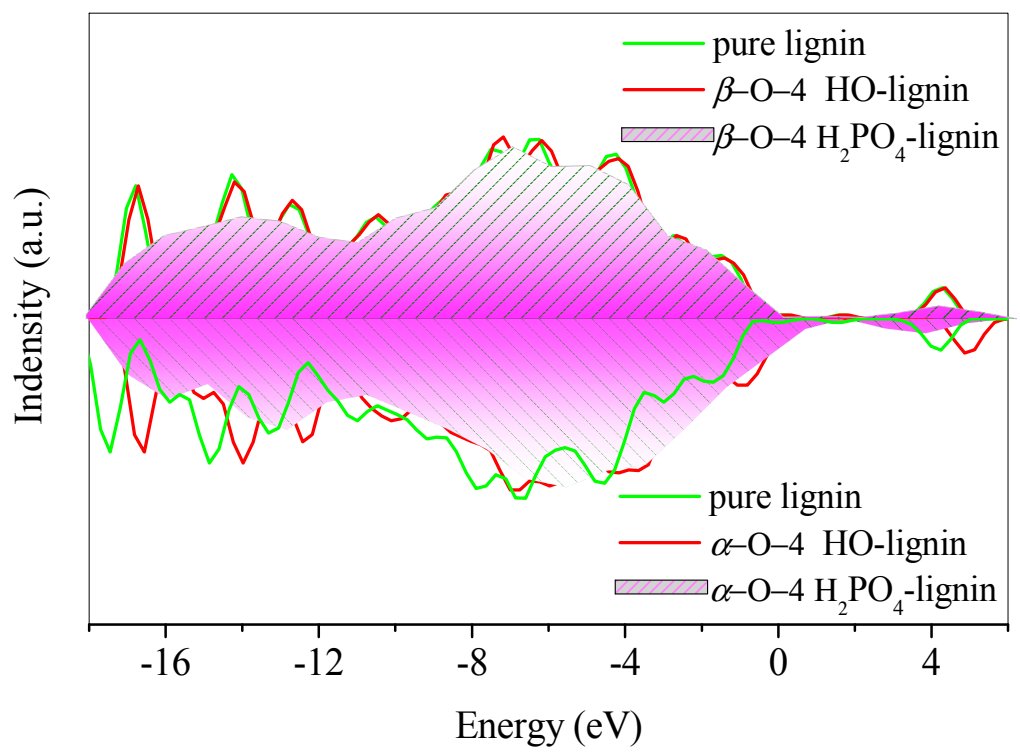

Further, we compared the HOMO and the LUMO of the lignin before and after hydrolysis and phosphorylation. Figure 6 illustrates the optimized structure of the pure lignin, and the products of phosphorylation and hydrolysis at $\alpha-O-4$ linkage and $\beta-O-4$ linkage, with the isosurface $(0.01)$ of the related HOMO and LUMO.

Figure 6. The optimized structure of (a) the pure lignin; (b) the HO-functionalized lignin at $\beta-O-4$ linkage; (c) the $\mathrm{H}_{2} \mathrm{PO}_{4}$-functionalized lignin at $\beta-O-4$ linkage; (d) the $\mathrm{HO}$-functionalized lignin at $\alpha-O-4$ linkage; and (e) the $\mathrm{H}_{2} \mathrm{PO}_{4}$-functionalized lignin at $\alpha-O-4$ linkage, with the isosurface (0.01) of the HOMO and the LUMO.

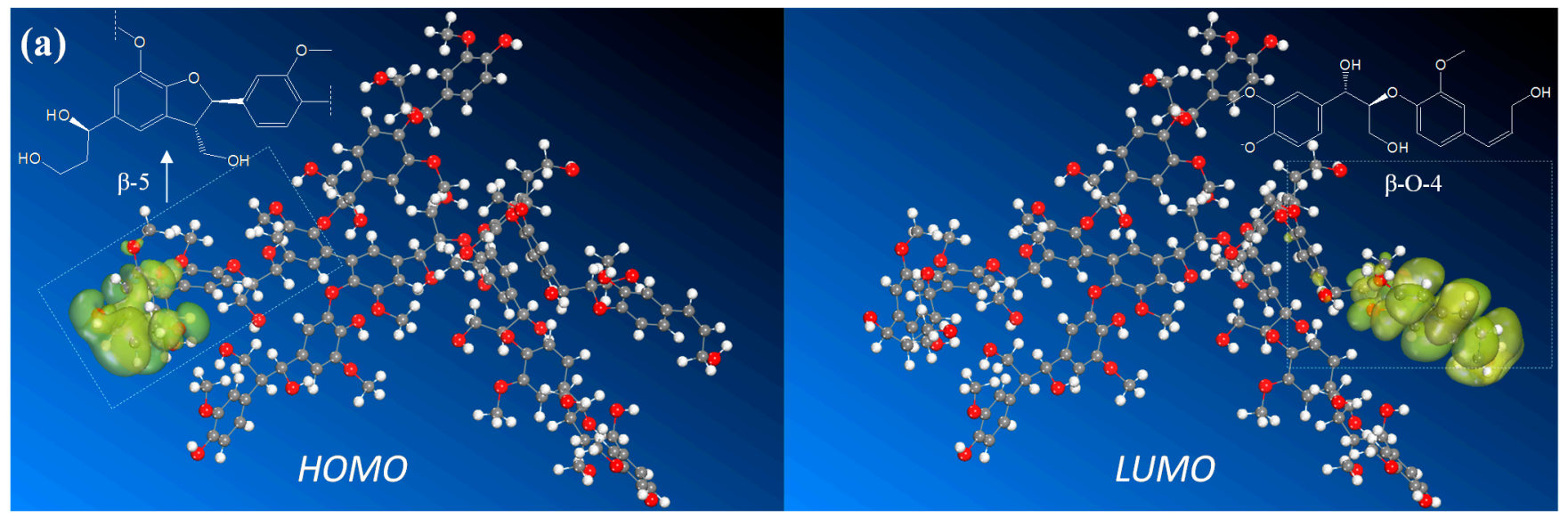


Figure 6. Cont.

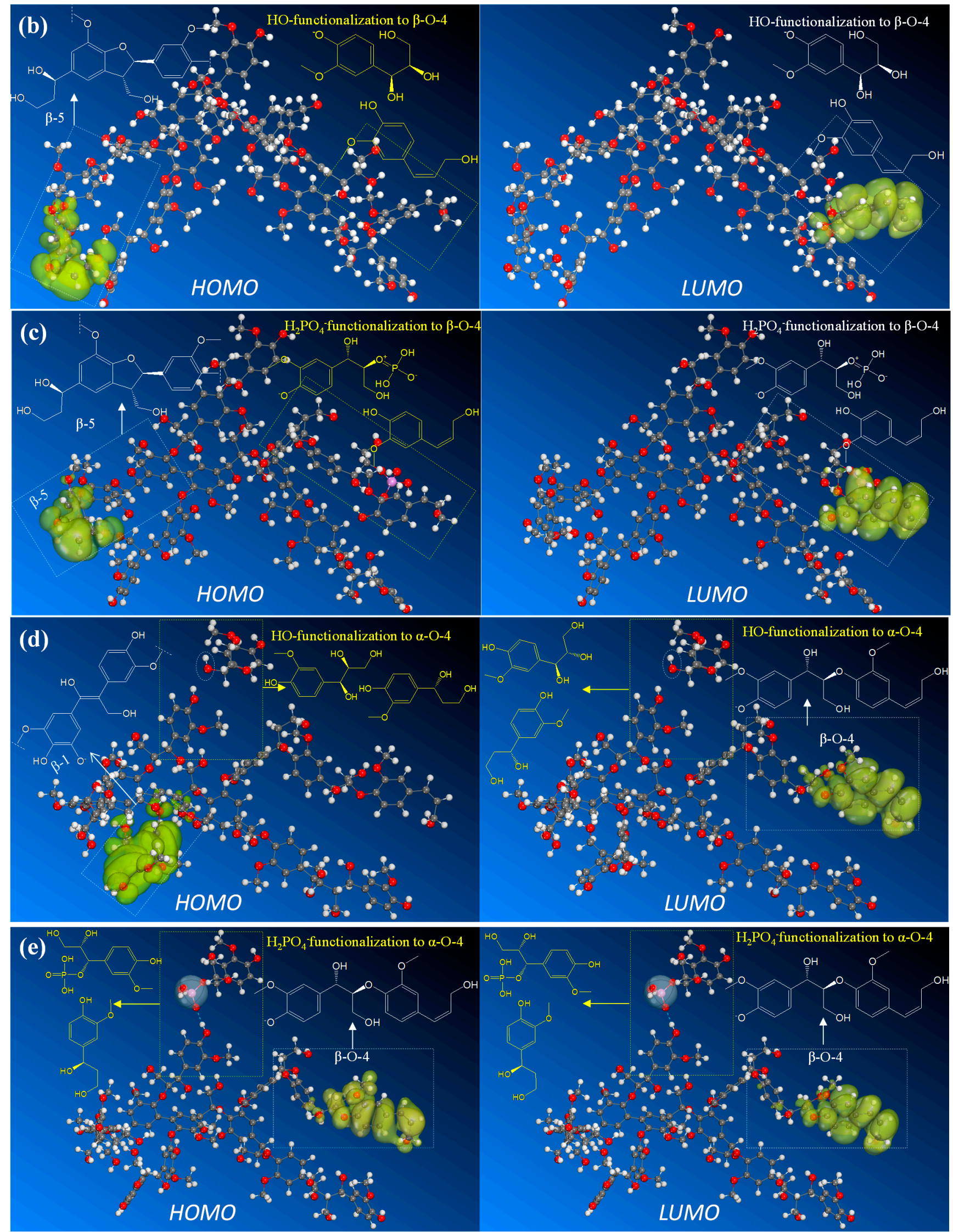


In Figure $6 \mathrm{a}$, the left side of $\beta-5$ contributes to the HOMO of the pure lignin system, while the right side of $\beta-O-4$ contributes to the LUMO of the pure lignin system. In Figure $6 \mathrm{~b}, \mathrm{c}$, the isosurfaces of HOMO and LUMO of the products of phosphorylation and hydrolysis at $\beta-O-4$ linkage are almost the same as those for the pure lignin in Figure 6a, which suggests that phosphorylation and hydrolysis at $\beta-O-4$ linkage never change the HOMO and LUMO of lignin.

However, differing from the pure lignin and the $\mathrm{H}_{2} \mathrm{PO}_{4}$-functionalized and $\mathrm{HO}$-functionalized lignin at $\beta-O-4$ linkage, $\mathrm{HO}$-functionalization at $\alpha-O-4$ linkage changes the $\mathrm{HOMO}$ of the lignin system, where $\beta-1$ contributes to the HOMO (as shown in Figure $6 \mathrm{~d}$ ), and $\mathrm{H}_{2} \mathrm{PO}_{4}$-functionalization at the $\alpha-O-4$ linkage results in that the right side of $\beta-O-4$ contributing to boththe HOMO and LUMO of the lignin system (as shown in Figure 6e). Clearly, the phosphorylation of $\alpha-O-4$ in phosphoric acid during the phosphoric acid-acetone pretreatment process of lignin, controls electron and hole transfer on the right side of $\beta-O-4$ in the functionalized lignin system. Therefore, the right side of $\beta-O-4$ can act as a special structure with certain functions for novel applications such as lignin-based imprinted polymers, sensors, and molecular devices.

\section{Computational Details}

The equilibrium structure of the model lignin in different solutions was obtained by performing molecular dynamics simulations with the LAMMPS program package [27], using the ReaxFF force field parametrizaion as described in [28]. Based on the equilibrium structure of the model lignin, density functional theory (DFT) calculations were used to investigate the detailed properties of lignin and the related reaction mechanisms in various solutions involved in the phosphoric acid-acetone pretreatment process in reference to the works [29-35]. In our work, DFT calculations were performed using the DMol3 package. The exchange-correlation energy of electrons was calculated with the spin-polarized generalized gradient approximation (GGA) [36] as implemented in the $\mathrm{DMol}^{3}$ package. The Perdew-Burke-Ernzerhof (PBE) exchange-correction functional [37] and the double numerical plus polarization (DNP) [38-40] basis set were used throughout the calculations, which is equivalent in accuracy to the commonly used $6-31 \mathrm{G}^{* *}$ of Gaussian orbital basis set. But the numerical basis set is much more accurate than a Gaussian basis set with the same size. The solvent effect was considered by using a solvation model with the appropriated dielectric constant, $\varepsilon$, where $\varepsilon$ was set to be $80.1,20$, and 12.7 for the aqueous solution, acetone, and phosphoric acid $(85 \% \mathrm{w} / \mathrm{w})$, in reference to the work of Wang [41] and Munson [42]. Specific interactions between lignin and the solvent molecules were not taken into account in this study, since the solvent is represented by a polarizable continuum with a particular dielectric constant. During the calculations, the atoms were relaxed and Brillouin zone integration was performed at the gamma point [43]. Calculations used an energy convergence tolerance of $1 \times 10^{-6} \mathrm{Ha}$ and gradient convergence of $1 \times 10^{-6} \mathrm{Ha} \cdot \AA^{-1}$. A formulation for the linear (LST) and quadratic synchronous transit (QST) methods was used to search the transition states and investigate lignin fragment decomposition [44].

\section{Conclusions}

We theoretically studied the lignin hydrolysis and phosphorylation mechanism during the phosphoric acid-acetone pretreatment process of lignin using density functional theory calculations. The lignin 
fragment with the seven most common linkages ( $\beta-O-4, \beta-\beta, 4-O-5, \beta-1,5-5, \alpha-O-4$, and $\beta-5)$ was modeled to detect the chemical stability of these linkages in $\mathrm{H}_{3} \mathrm{PO}_{4}, \mathrm{CH}_{3} \mathrm{COCH}_{3}$, and $\mathrm{H}_{2} \mathrm{O}$ solutions present during the phosphoric acid-acetone pretreatment process. $5-5, \beta-1, \beta-5, \beta-\beta$, and $4-O-5$ are chemically stable to maintain the relative structural integrity of lignin, while partial structural damage will happen to lignin due to the relative vulnerability of $\beta-O-4$ and $\alpha-O-4$. Then two-step phosphorylation reaction happened at $\alpha-O-4$ linkage as the major modification to lignin in $\mathrm{H}_{3} \mathrm{PO}_{4}$ solution, where $\mathrm{H}_{2} \mathrm{PO}_{4}{ }^{-}$group bound to $\mathrm{C}_{\alpha}$, resulting in a stable configuration of $\mathrm{H}_{2} \mathrm{PO}_{3}-O$-lignin species. $\mathrm{H}_{2} \mathrm{PO}_{4}$-functionalization at $\alpha-O-4$ linkage could controlled electron and hole transfer on the right ring of $\beta-O-4$ in the $\mathrm{H}_{2} \mathrm{PO}_{3}-O$-lignin species. Results provide a fundamental understanding for process-controlled modification of lignin and potential novel applications in lignin-based imprinted polymers, sensors, and molecular devices.

\section{Acknowledgments}

The authors wish to thank the National Natural Science Foundation of China (51106051), the National Key Technology R\&D Program (2012BAA09B01), the 111 Project (B12034) and the Fundamental Research Funds for the Central Universities (2014MS36, 2014ZD14).

\section{Author Contributions}

$\mathrm{Wu}$ Qin performed all the research work and wrote the paper. Lingnan $\mathrm{Wu}$, Zongming Zheng, Changqing Dong and Yongping Yang designed research and edited the paper. All authors have read, edited, and approved the final version of the paper.

\section{Conflicts of Interest}

There is no conflict of interest among the authors.

\section{References}

1. Lebo, S.E., Jr.; Gargulak, J.D.; McNally, T.J. Lignin. In Kirk-Othmer encyclopedia of chemical technology; Wiley-Interscience: New York, NY, USA, 2001; Volume 15, pp. 1-32. doi:10.1002/0471238961.12090714120914.a01.pub2.

2. Martone, P.T.; Estevez, J.M.; Lu, F.; Ruel, K.; Denny, M.W.; Somerville, C.; Ralph, J. Discovery of lignin in seaweed reveals convergent evolution of cell-wall architecture. Curr. Biol. 2009, 19, 169-175.

3. Pauly, M.; Keegstra, K. Cell-wall carbohydrates and their modification as a resource for biofuels. Plant J. 2008, 54, 559-568.

4. Doherty, W.O.; Mousavioun, P.; Fellows, C.M. Value-adding to cellulosic ethanol: Lignin polymers. Ind. Crops Prod. 2011, 33, 259-276.

5. Cybulska, I.; Brudecki, G.; Rosentrater, K.; Julson, J.L.; Lei, H. Comparative study of organosolv lignin extracted from prairie cordgrass, switchgrass and corn stover. Bioresour. Technol. 2012, 118, $30-36$.

6. Lora, J.H.; Glasser, W.G. Recent industrial applications of lignin: A sustainable alternative to nonrenewable materials. J. Polym. Environ. 2002, 10, 39-48. 
7. Cazacu, G.; Pascu, M.C.; Profire, L.; Kowarski, A.; Mihaes, M.; Vasile, C. Lignin role in a complex polyolefin blend. Ind. Crops Prod. 2004, 20, 261-273.

8. Nadif, A.; Hunkeler, D.; Käuper, P. Sulfur-free lignins from alkaline pulping tested in mortar for use as mortar additives. Bioresour. Technol. 2002, 84, 49-55.

9. Ugartondo, V.; Mitjans, M.; Vinardell, M.P. Comparative antioxidant and cytotoxic effects of lignins from different sources. Bioresour. Technol. 2008, 99, 6683-6687.

10. Reti, C.; Casetta, M.; Duquesne, S.; Bourbigot, S.; Delobel, R. Flammability properties of intumescent PLA including starch and lignin. Polym. Adv. Technol. 2008, 19, 628-635.

11. Zhang, Y.-H.P.; Cui, J.; Lynd, L.R.; Kuang, L.R. A transition from cellulose swelling to cellulose dissolution by $o$-phosphoric acid: Evidence from enzymatic hydrolysis and supramolecular structure. Biomacromolecules 2006, 7, 644-648.

12. Zhang, Y.H.P.; Ding, S.Y.; Mielenz, J.R.; Cui, J.B.; Elander, R.T.; Laser, M.; Himmel, M.E.; McMillan, J.R.; Lynd, L.R. Fractionating recalcitrant lignocellulose at modest reaction conditions. Biotechnol. Bioeng. 2007, 97, 214-223.

13. Moxley, G.; Zhu, Z.; Zhang, Y.-H.P. Efficient sugar release by the cellulose solvent-based lignocellulose fractionation technology and enzymatic cellulose hydrolysis. J. Agric. Food Chem. 2008, 56, 7885-7890.

14. Kim, J.; Mazza, G. Optimization of phosphoric acid catalyzed fractionation and enzymatic digestibility of flax shives. Ind. Crops Prod. 2008, 28, 346-355.

15. Ramos, L.A.; Assaf, J.M.; El Seoud, O.A.; Frollini, E. Influence of the supramolecular structure and physicochemical properties of cellulose on its dissolution in a lithium chloride $/ N$, $\mathrm{N}$-dimethylacetamide solvent system. Biomacromolecules 2005, 6, 2638-2647.

16. Dorrestijn, E.; Laarhoven, L.J.; Arends, I.W.; Mulder, P. The occurrence and reactivity of phenoxyl linkages in lignin and low rank coal. J. Anal. Appl. Pyrolysis 2000, 54, 153-192.

17. Beste, A. ReaxFF study of the oxidation of lignin model compounds for the most common linkages in softwood in view of carbon fiber production. J. Phys. Chem. A 2014, 118, 803-814.

18. Kang, P.; Zheng, Z.; Qin, W.; Dong, C.; Yang, Y. Efficient fractionation of Chinese white poplar biomass with enhanced enzymatic digestibility and modified acetone-soluble lignin. BioResources 2011, 6, 4705-4720.

19. Huajing, W.; Wang, Z.Y.; Yao, C.F.; Qingxiang, G. Theoretical study on the pyrolysis process of lignin dimer model compounds. Acta Chim. Sin. 2009, 67, 893-900.

20. Younker, J.M.; Beste, A.; Buchanan, A.C., III. Computational study of bond dissociation enthalpies for lignin model compounds: $\beta-5$ arylcoumaran. Chem. Phys. Lett. 2012, 545, 100-106.

21. Kim, S.; Chmely, S.C.; Nimlos, M.R.; Bomble, Y.J.; Foust, T.D.; Paton, R.S.; Beckham, G.T. Computational study of bond dissociation enthalpies for a large range of native and modified lignins. J. Phys. Chem. Lett. 2011, 2, 2846-2852.

22. Sturgeon, M.; Kim, S.; Lawrence, K.; Paton, R.S.; Chmely, S.C.; Nimlos, M.R.; Foust, T.D.; Beckham, G.T. A mechanistic investigation of acid-catalyzed cleavage of aryl-ether linkages: Implications for lignin depolymerization in acidic environments. ACS Sustain. Chem. Eng. 2014, 2, 472-485.

23. Nada, A.M.; Kassem, N.F.; Mohamed, S.H. Characterization and properties of ion exchangers produced from lignin precipitated after peroxyacid pulping. BioResources 2008, 3, 538-548. 
24. Janesko, B.G. Acid-catalyzed hydrolysis of lignin $\beta-O-4$ linkages in ionic liquid solvents: A computational mechanistic study. Phys. Chem. Chem. Phys. 2014, 16, 5423-5433.

25. Henry, N.W. Polymer Nanocomposite Analysis and Optimization for Renewable Energy and Materials. Ph.D. Thesis, The University of Tennessee, Knoxville, TN, USA, December 2011.

26. Abdel-kader, A. Preparation of lignin from waste black liquors as ion exchangers. Der Chem. Sin. 2012, 3, 689-697.

27. Plimpton, S. Fast parallel algorithms for short-range molecular dynamics. J. Comput. Phys. 1995, $117,1-19$.

28. Chenoweth, K.; van Duin, A.C.T.; Goddard, W.A., III. ReaxFF reactive force field for molecular dynamics simulations of hydrocarbon oxidation. J. Phys. Chem. A 2008, 112, 1040-1053.

29. Durbeej, B.; Eriksson, L.A. Spin distribution in dehydrogenated coniferyl alcohol and associated dilignol radicals. Holzforschung 2003, 57, 59-61.

30. Durbeej, B.; Eriksson, L.A. A density functional theory study of coniferyl alcohol intermonomeric cross linkages in lignin-Three-dimensional structures, stabilities and the thermodynamic control hypothesis. Holzforschung 2003, 57, 150-164.

31. Beste, A.; Buchanan, A.C., 3rd; Britt, P.F.; Hathorn, B.C.; Harrison, R.J. Kinetic analysis of the pyrolysis of phenethyl phenyl ether: Computational prediction of $\alpha / \beta$-selectivities. J. Phys. Chem. A 2007, 111, 12118-12126.

32. Beste, A.; Buchanan, A.C., 3rd; Harrison, R.J. Computational prediction of $\alpha / \beta$ selectivities in the pyrolysis of oxygen-substituted phenethyl phenyl ethers. J. Phys. Chem. A 2008, 112, 4982-4988.

33. Beste, A.; Buchanan, A.C., 3rd. Computational study of bond dissociation enthalpies for lignin model compounds. Substituent effects in phenethyl phenyl ethers. J. Org. Chem. 2009, 74, 2837-2841.

34. Beste, A.; Buchanan, A.C., 3rd. Substituent effects on the reaction rates of hydrogen abstraction in the pyrolysis of phenethyl phenyl ethers. Energy Fuels 2010, 24, 2857-2867.

35. Durbeej, B.; Eriksson, L.A. Formation of $\beta-O-4$ lignin models-a theoretical study. Holzforschung 2003, 57, 466-478.

36. Perdew, J.P.; Burke, K.; Wang, Y. Generalized gradient approximation for the exchange-correlation hole of a many-electron system. Phys. Rev. B 1996, 54, 16533.

37. Perdew, J.P.; Burke, K.; Ernzerhof, M. Generalized Gradient Approximation Made Simple. Phys. Rev. Lett. 1996, 77, 3865-3868.

38. Delley, B. An all-electron numerical method for solving the local density functional for polyatomic molecules. J. Chem. Phys. 1990, 92, 508-517.

39. Delley, B. From molecules to solids with the $\mathrm{DMol}^{3}$ approach. J. Chem. Phys. 2000, 113, 7756-7764.

40. Delley, B. Fast calculation of electrostatics in crystals and large molecules. J. Phys. Chem. 1996, 100, 6107-6110.

41. Wang, P.; Anderko, A. Computation of dielectric constants of solvent mixtures and electrolyte solutions. Fluid Phase Equilibria 2001, 186, 103-122.

42. Munson, R.A. Dielectric constant of phosphoric acid. J. Chem. Phys. 1964, 40, 2044-2046.

43. Kudin, K.N.; Ozbas, B.; Schniepp, H.C.; Prud'Homme, R.K.; Aksay, I.A.; Car, R. Raman spectra of graphite oxide and functionalized graphene sheets. Nano Lett. 2008, 8, 36-41. 
44. Govind, N.; Petersen, M.; Fitzgerald, G.; King-Smith, D.; Andzelm, J. A generalized synchronous transit method for transition state location. Comput. Mater. Sci. 2003, 28, 250-258.

Sample Availability: Not available.

(C) 2014 by the authors; licensee MDPI, Basel, Switzerland. This article is an open access article distributed under the terms and conditions of the Creative Commons Attribution license (http://creativecommons.org/licenses/by/4.0/). 